\title{
Multiple equilibria, fiscal policy, and human capital accumulation*
}

\author{
Jaime Alonso-Carrera** \\ and \\ María Jesús Freire -Serén \\ Universidade de Vigo
}

This version, July 2002

\begin{abstract}
This paper shows that in a three-sector model of endogenous growth with physic al and human capital accumulation, taxation policy can generate indeterminacy under plausible parameterizations. The key for this result is that the accumulation of human capital is a non-market activity in which individuals combine their non-working time with intermediate goods that are provided by the market. This assumption is consistent with the microfoundations of human capital accumulation found by the literature on life-cycle earnings.
\end{abstract}

Key Words: indeterminacy; human capital investment; economic growth; fiscal policy.

JEL Classification Numbers: E32; E62; O41

\footnotetext{
* We are indebted to Xavier Raurich and Jesús Vázquez for their very useful discussions and comments. Of course, all errors that remain are entirely my own. The authors acknowledge the financial support from the Spanish Ministry of Education through DGICYT grants SEC99-1094 and SEC99-1189, respectively. Moreover, María Jesús Freire -Serén also acknowledges the financial support from Fundación PROVIGO.

** Correspondence address: Jaime Alonso-Carrera, Facultade de Ciencias Económicas, Universidade de Vigo, Campus Lagoas Marcosende, 36200, Vigo, Spain. Phone: +34 986812 504. Fax: +34 986812 401. Email: jalonso@uvigo.es.
} 


\section{Introduction}

In recent years, there has been an extensive literature that examines the existence of indeterminate equilibria in dynamic general equilibrium models. ${ }^{1}$ The motivation of this search is that indeterminacy is able to account for endogenous business fluctuations and for some empirically observed growth episodes that cannot be reconciled with more traditional literature. ${ }^{2}$ The possibility of a continuum of equilibria is the consequence of some market imperfections. Usually, the imperfections are assumed to come from external effects in production or monopolistic competition. Furthermore, it has been showed that indeterminacy appears under empirically realistic assumptions.

The intent of this paper is to show that multiple equilibria can also arise straightforwardly without abandoning the hypotheses of perfect competition and absence of externalities. We argue that the market imperfections generated by the taxation policy can generate indeterminacy in a three-sector endogenous growth model with physical and human capital accumulation. As a crucial ingredient for our result, we depart from the traditional endogenous growth model with human capital accumulation by making deeper the microfoundations of the process of human capital accumulation. We specify the accumulation of human capital as a non-market activity that uses effective labor and goods (and services) acquired in the market (intermediate goods, henceforth) as inputs. Therefore, the investment in human capital has a direct component given by the purchases of intermediate goods and an indirect component given by the opportunity cost of the time spent in accumulating human capital. While the former component is perfect substitute of physical capital investment and consumption, the later component is no perfect substitute of those alternative allocations of income. Both components are empirically relevant. For instance, Perli and Sakellaris (1998) estimate the

\footnotetext{
${ }^{1}$ See Benhabib and Farmer (1999) for a complete survey of this literature.

2 See Benhabib and Gali (1995) for an overview of the empirical predictions of growth models with multiple equilibria.
} 
total educational expenditures and the foregone labor income of students in US at $8 \%$ and $3.6 \%$ of GNP, respectively.

Traditionally, the endogenous growth models with human capital accumulation have often alternatively considered only one of these two components of human capital investment. Some models assume that human capital accumulation is a pure non-market activity (see, e.g., Lucas, 1988). Other models instead consider that human capital accumulation is a pure market activity where individuals increase their human capital by directly acquiring the intermediate goods without any other manipulation (see, e.g., Rebelo and Stokey, 1995). By contrast, Jones, Manuelli and Rossi (1993) also specified a process of human capital accumulation like ours. However, they postulate a two-sector model in which human capital accumulation requires market consumption goods and effective labor. We instead consider a third sector whereby intermediate goods are first produced with a specific technology that uses physical capital and effective labor as inputs. These intermediate goods are then used exclusively, together with effective labor, for the accumulation of human capital. As was pointed out by Schultz (1961), there are a bundle of market goods and services that enhance labor efficiency with cost of time, and however they do not directly satisfy any preferences underlying consumption. ${ }^{3}$ Since these goods and services are not perfect substitutes of consumable goods, it seems reasonable to assume here different technologies for the production of both types of goods. Hence, we will adopt the two-stage process of human capital accumulation proposed by Ghez and Becker (1975) and Heckman (1976) in their life-cycle models of earnings.

We complete the model with the introduction of a tax on physical capital income, a tax on labor income, a subsidy to the purchase of intermediate goods and a subsidy to the opportunity cost of accumulating human capital. We will prove that the fiscal policy mix determines the equilibrium dynamics. Our fiscal policy scheme introduces a gap between the factors intensity ranking across

\footnotetext{
3 Textbooks, medicines or educational services from schools, colleges and universities are, among others, examples of these non-consumable goods. In reality, this process of human capital accumulation also uses a vector of consumable goods. However, we omit this possibility to clarify, without losing of generality, the exposition and contribution of the paper.
} 
sectors in terms of cost shares and the ranking in terms of factor quantity ratios. When this distortion is sufficiently high, the previous rankings of factor intensities are no consistent. In this case, the standard duality between Rybczynski and Stolper-Samuelson effects, which determines the existence of a unique equilibrium of the usual saddle-path type in multi-sector growth models, is broken. ${ }^{4}$ In particular, the equilibrium is locally indeterminate when the entire process of human capital accumulation is relatively more intensive in human capital at the private level (i.e., in terms of the factor quantity ratios), while this process is relatively more intensive in physical capital at the social level (i.e., in terms of the factor cost shares).

In a recent paper, Bond, Wang and Yip (1996) also examine the effects of distortionary factor taxation in a two-sector model where the accumulation of human capital is a pure non-market activity. However, they obtain indeterminacy under an atypical sectoral configuration where the production of new human capital is relatively more intensive in physical capital at the private level, while it is relatively more intensive in human capital at the social level. Benhabib, Meng and Nishimura (2000) and Mino (2001) have also obtained this result in two-sector models with social constant returns to scale and sector-specific externalities. In fact, Bond, Wang and Yip (1996) consider a fiscal policy scheme that is formally equivalent to sector-specific external effects. They consider an asymmetry between capital and labor taxation since labor in human capital sector is untaxed while capital taxation affects the earnings of physical capital in both sectors.

The key difference between the contribution of Bond, Wand and Yip (1996) and the present study is that our three-sector production structure makes compatible a sector-specific fiscal policy with a symmetric fiscal treatment between capital and labor in each sector and with a uniform taxation of each factor across the two market sectors. In this sense, the results of the present paper resemble those obtained by Drugeon, Poulsen and Venditti (2002). Based on "labor-augmenting" intersectoral external effects stemming from the aggregate capital stock, they obtain indeterminacy when the pure capital good is relatively intensive in itself at the private level.

\footnotetext{
4 The role of the factor intensity ranking in the transitional dynamics of multi-sector growth models is extensively presented in Bond, Wang and Yip (1996).
} 
The paper is organized as follows. In Section 2 we present the model. Section 3 characterizes the equilibrium dynamics, analyzing the conditions for the multiplicity of equilibrium paths. Section 4 briefly discusses the economic mechanism underlying the possibility of multiple equilibria. Some lengthy proofs are contained in the appendix.

\section{The Model}

Let us consider an economy populated by a continuum of identical, everlasting households. For convenience, we assume that population growth is zero and normalize population size to one. The households' preferences are represented by

$$
U=\int_{0}^{\infty}\left(\frac{C(t)^{1-\sigma}-1}{1-\sigma}\right) e^{-\rho t} d t
$$

where $C(t)$ is consumption, $\rho>0$ is the constant subjective rate of time preferences, and $\sigma>0$

denotes the inverse of the constant elasticity of inter-temporal substitution. Each household is endowed with a unit of time that is allocated to labor, and to accumulating human capital. If $l(t)$ denotes the fraction of time devoted to labor, then the effective labor supplied by the household is $l(t) h(t)$, where $h(t)$ is the per capita stock of human capital.

There are three productive sectors in this economy. The first one produces a homogenous physical good, $Y(t)$, which can be either consumed or added to the stock of physical capital, $K(t)$. This physical good is produced according to the Cobb-Douglas technology

$$
Y(t)=A(v(t) K(t))^{\beta}(u(t) h(t))^{1-\beta}=A u(t) h(t) z_{1}(t)^{\beta},
$$

where $A>0$ is the scale factor, $v(t)$ and $u(t)$ are respectively the shares of physical capital and human capital allocated to the physical goods sector, and $z_{1}(t)=[v(t) K(t)] /[u(t) h(t)]$. The second sector produces an intermediate good, $E(t)$, which is acquired by households to increase their stock of human capital. In this sector, we also posit a Cobb-Douglas production function, with 


$$
E(t)=B((1-v(t)) K(t))^{\alpha}((l(t)-u(t)) h(t))^{1-\alpha}=B(l(t)-u(t)) h(t) z_{2}(t)^{\alpha},
$$

where $B>0$ is the scale factor, and $z_{2}(t)=[(1-v(t)) K(t)] /[(l(t)-u(t)) h(t)]$. Finally, the third sector involves non-market activities resulting in increases of households' stock of human capital, which enhances the efficiency units of their labor supply. We assume that households need to spend time in manipulating the intermediate goods so as to increase their stock of human capital. ${ }^{5}$ More precisely, we postulate a Cobb-Douglas technology of human capital production. Hence, the law of motion of human capital stock is

$$
\dot{h}(t)=\gamma I_{h}(t)^{\theta}((1-l(t)) h(t))^{1-\theta}-\eta h(t),
$$

where $I_{h}$ represents the gross investment demand for intermediate goods from each household, and $\eta \geq 0$ is the constant rate of depreciation of human capital stock.

The government in this economy sets a flat-rate tax, $t_{k}$, on physical capital income, a flat-rate tax, $t_{h}$, on labor income, a flat-rate subsidy, $s_{E}$, to the purchases of intermediate goods, and a flatrate subsidy, $s_{w}$, to the before-tax opportunity cost of accumulating human capital. We assume that the government faces a balanced budget constraint in each moment in time, that is,

$$
T(t)=t_{k} r(t) K(t)+t_{h} w(t) l(t) h(t)-s_{E} p(t) I_{h}(t)-s_{w} w(t)(1-l(t)) h(t),
$$

where $T(t)$ is either a lump-sum tax or a lump-sum transfer depending on the sign of the right hand side of (5), $r(t)$ is the rental rate of physical capital, $w(t)$ is the wage rate, and $p(t)$ is the relative price of intermediate goods in units of physical goods. The budget constraint of a household is thus

$$
\begin{aligned}
\left(1-t_{k}\right) r(t) K(t)+\left(1-t_{h}\right) w(t) l(t) & h(t)+s_{w} w(t)(1-l(t)) h(t) \\
& =C(t)+\dot{K}(t)+\left(1-s_{E}\right) p(t) I_{h}(t)+T(t)-\delta K(t),
\end{aligned}
$$

where $\delta \geq 0$ is the constant rate of depreciation of physical capital stock.

\footnotetext{
5 The same assumption may be made for the accumulation of physical capital and consumption. We omit this possibility to facilitate the exposition and the understanding of our results and conclusions.
} 
Given the initial stocks of physical and human capital, which we will respectively denotes by $K_{0}$ and $h_{0}$, and fiscal policy $\left\{t_{k}, t_{h}, s_{E}, s_{w}\right\}$, a competitive equilibrium under balanced budget is defined as a set of path for prices $\{r(t), w(t), p(t)\}$, allocations $\left\{C(t), l(t), v(t), u(t), I_{h}(t), T(t)\right\}$, and both capital stocks $\{K(t), h(t)\}$, such that

(i) the representative household's choice of the paths $\left\{C(t), l(t), I_{h}(t), K(t), h(t)\right\}$ maximizes (1) subject to (6), (4) and to non-negativity constraints on all variables;

(ii) the paths $\{v(t), u(t), K(t), h(t)\}$ maximize firms' profits;

(iii) the government obeys its inter-temporal budget constraint (5); and

(iv) the market-clearing conditions for physical goods and for intermediate goods hold, i.e.,

$$
\begin{aligned}
& Y(t)=C(t)+\dot{K}(t)-\delta K(t), \\
& E(t)=I_{h}(t) .
\end{aligned}
$$

In equilibrium, competition among profit-maximizing firms ensures that both factors are paid their marginal products. Hence, if both physical capital and human capital are perfectly mobile across sectors, the profit maximization conditions are

$$
\begin{aligned}
& r(t)=\beta A z_{1}(t)^{\beta-1}=p(t) \alpha B z_{2}(t)^{\alpha-1}, \\
& w(t)=(1-\beta) A z_{1}(t)^{\beta}=p(t)(1-\alpha) B z_{2}(t)^{\alpha} .
\end{aligned}
$$

The representative household's problem involves three margins. First, total income must be allocated between consumption of physical goods and total investments. This implies that the marginal substitution between consumption at different dates must equalize its corresponding relative price, i.e.,

$$
e^{-\rho t} \frac{C(t)^{-\sigma}}{C(0)^{-\sigma}}=e^{-R(0, t)}
$$


where $R(0, t)=\int_{o}^{t}\left[\left(1-t_{k}\right) r(s)-\delta\right] d s$ is the cumulative rate of return between the initial period and time $t$.

Secondly, income allocated to total investments must be efficiently distributed between the accumulation of physical capital and the purchase of intermediate goods. The optimal portfolio selection is given by the equality between the marginal return of a unit invested in the accumulation of each capital. Thus, since the present value of the cost and the benefit of investing in physical capital is the unit, the portfolio selection is given by the following non- arbitrage condition:

$$
\left(1-s_{E}\right) p(t)=\theta \gamma I_{h}(t)^{\theta-1}((1-l(t)) h(t))^{1-\theta} V(t),
$$

where $V(t)$ is the discounted marginal value of the household's human capital stock at time $t$, i.e.,

$$
V(t)=\int_{0}^{\infty} e^{G(t, \tau)-R(t, \tau)}\left[\left(1-t_{h}\right) l(\tau)+s_{w}(1-l(\tau))\right] w(\tau) d t
$$

where $G(t, \tau)=\int_{t}^{\tau}\left[\gamma I_{h}(s)^{\theta}(1-l(s))^{1-\theta} h(s)^{-\theta}-\eta\right] d s$ is the cumulative variation of the human capital stock between time $t$ and $\tau$ caused by a marginal change in $h(t)$, and $R(t, \tau)$ is the cumulative rate of return between time $t$ and $\tau .6$

Finally, the endowment of time must be allocated between labor supply and human capital accumulation. Optimally means that the household gets the same marginal revenue in each of them, i.e.,

$$
\left(1-t_{h}-s_{w}\right) w(t)=(1-\theta) \gamma I_{h}(t)^{\theta}((1-l(t)) h(t))^{-\theta} V(t) .
$$

\footnotetext{
${ }^{6}$ Note that the discounted value of a household's total income from human capital at any time $t$ is equal to

$$
W(t)=\int_{0}^{\infty} e^{-R(t, \tau)}\left[\left(1-t_{h}\right) l(\tau)+s_{w}(1-l(\tau))\right] w(\tau) h(\tau) d \tau .
$$

The income generated by the human capital stock at any time $\tau$ is twofold. First, the fraction of time in efficiency units of labor allocated to working obtains an after-tax labor income. Second, the fraction of time allocated to accumulating human capital also obtains a subsidy per unit of foregone labor income. Using the law of motion of human capital (4), Expression (12) is easily obtained from the definition of $W(t)$.
} 
The competitive equilibrium is then fully characterized by Eqs. (4), (5), (6), (7), (8), (9), (10), (11) and (13), the usual transversality conditions, ${ }^{7}$ and the initial values $K_{0}$ and $h_{0}$.

For notational convenience, we index the fundamentals of the model economy by the vector of parameters $\pi$. We then define $\pi \equiv\left(A, B, \gamma, \rho, \sigma, \delta, \eta, \alpha, \beta, \theta, t_{k}, t_{h}, s_{E}, s_{w}\right)$, and $\pi \in \Pi$, where $\Pi=R_{++}^{5} \times R_{+}^{2} \times(0,1)^{3} \times[0,1]^{4}$.

\section{The Equilibrium Dynamics}

In the environment described in the previous section, the dynamic behavior of the economic variables crucially depends on the fiscal policy. Under some combinations of fiscal instruments, the equilibrium dynamics may be not defined by the usual property of saddle-path stability. In this section, we will characterize the dynamic behavior of the economy along the equilibrium. For that purpose, we first construct the dynamic system that fully describes the competitive equilibrium paths. As a necessary step, we reduce the relevant explanatory variables of the model. Assuming that both sectors are active, one can explicitly solve for the factor intensities in each sector, the relative price and shares of both types of capitals in each technology as functions of $K(t), h(t)$ and $V(t) .{ }^{8}$ First, we get from (9) and (11) that

$$
\begin{aligned}
& z_{1}(t) \equiv z_{1}(V(t))=\left(\frac{\beta}{1-\beta}\right) \phi \Omega^{1 / \beta-\alpha} V(t)^{1 / \beta-\alpha \theta}, \\
& z_{2}(t) \equiv z_{2}(V(t))=\left(\frac{\alpha}{1-\alpha}\right) \phi \Omega^{1 / \beta-\alpha} V(t)^{1 / \beta-\alpha \theta}, \\
& p(t) \equiv p(V(t))=\Omega V(t)^{\beta-\alpha / \beta-\alpha \theta},
\end{aligned}
$$

where

\footnotetext{
7 These conditions are standard and impose that the present discounted value of both capital stocks tends to zero at the infinity.

${ }^{8}$ See the appendix for a detailed derivation of these expressions.
} 


$$
\begin{aligned}
& \phi=\left\lfloor\left(\frac{\beta A}{\alpha B}\right)\left(\frac{\alpha}{1-\alpha}\right)^{1-\alpha}\left(\frac{\beta}{1-\beta}\right)^{\beta-1}\right\rceil^{1 / \alpha-\beta}, \\
& \Omega=\left\lfloor\left(\frac{\gamma \theta}{1-s_{E}}\right)(B \Psi)^{\theta-1}\left(\frac{\alpha \phi}{1-\alpha}\right)^{\alpha(\theta-1)}\right\rceil^{\beta-\alpha / \beta-\alpha \theta}, \\
& \Psi=\left(\frac{\theta(1-\alpha)}{1-\theta}\right)\left(\frac{1-t_{h}-s_{w}}{1-s_{E}}\right) .
\end{aligned}
$$

Moreover, manipulating Conditions (11) and (13) with Eqs. (8), (9) and (14), we also get

$$
\begin{aligned}
& l(t) \equiv l(K(t) / h(t), V(t))=\frac{[K(t) / h(t)]+\Psi\left[z_{1}(t)-z_{2}(t)\right]}{z_{1}(t)+\Psi\left[z_{1}(t)-z_{2}(t)\right]}, \\
& u(t) \equiv u(K(t) / h(t), V(t))=\frac{[K(t) / h(t)]+\Psi\left[(K(t) / h(t))-z_{2}(t)\right]}{z_{1}(t)+\Psi\left[z_{1}(t)-z_{2}(t)\right]}, \\
& v(t) \equiv v(K(t) / h(t), V(t))=\left(\frac{z_{1}(t)}{[K(t) / h(t)]}\right)\left(\frac{[K(t) / h(t)]+\Psi\left[(K(t) / h(t))-z_{2}(t)\right]}{z_{1}(t)+\Psi\left[z_{1}(t)-z_{2}(t)\right]}\right) .
\end{aligned}
$$

At this point, we can fully characterize the dynamic behavior of the economy along an interior equilibrium through a system of first order differential equations in $K(t), h(t), C(t)$ and $V(t)$. Using Eqs. (4), (5), (6), (7), (8), (9), (10), (11), (12), (13), (14) and (15), we get

$$
\begin{aligned}
& \dot{K}(t)=A u(K(t) / h(t), V(t)) h(t)\left[z_{1}(V(t))\right]^{\beta}-C(t)-\delta K(t), \\
& \dot{h}(t)=\gamma B^{\theta} \Psi^{\theta}[1-l(K(t) / h(t), V(t))]\left[z_{2}(V(t))\right]^{\alpha \theta} h(t)-\eta h(t), \\
& \dot{C}(t)=(C(t) / \sigma)\left(\left(1-t_{k}\right) \beta A\left[z_{1}(V(t))\right]^{\beta-1}-\delta-\rho\right), \\
& \dot{V}(t)=\left(\left(1-t_{k}\right) \beta A\left[z_{1}(V(t))\right]^{\beta-1}-\delta+\eta\right) V(t)-\left(1-t_{h}\right)(1-\beta) A\left[z_{1}(V(t))\right]^{\beta} .
\end{aligned}
$$

At a balanced growth path (BGP, henceforth) the stock of physical capital, the stock of human capital and consumption grow at constant rates, and the factor shares in the technologies are constant. Hence, we see from (16c) and (14a) that $V(t)$ is also constant along a BGP. 
Furthermore, given the definition of $z_{1}(t)$, the previous property implies that the growth rate of $K(t)$ in a BGP must therefore be the same as $h(t)$ since $u(t)$ and $v(t)$ are constant. Finally, dividing (16a) by $K(t)$, we get that $K(t)$ must grow at the same rate as $C(t)$ along a BGP. As is customary in the economic growth literature, we shall focus on cases in which the economy exhibits interior BGPs, along which prices and resource allocations are constant and strictly positive. The next proposition establishes the existence and the uniqueness of an interior BGP.

PROPOSITION 1. Consider the economy described by Eqs. (4), (5), (6), (7), (8), (9), (10), (11) and (13). There exists at most an interior BGP equilibrium.

Proof. After making $\dot{V}(t)=0$, and using (14a), Eq. (16d) can be written as

$$
\delta-\eta=\left(1-t_{k}\right) \beta A\left(\left(\frac{\beta}{1-\beta}\right) \phi \Omega^{1 / \beta-\alpha}\right)^{\beta-1} V^{*}{ }^{\beta-1 / \beta-\alpha \theta}-\left(1-t_{h}\right)(1-\beta) A\left(\left(\frac{\beta}{1-\beta}\right) \phi \Omega^{1 / \beta-\alpha}\right)^{\beta} V^{* \alpha \theta / \beta-\alpha \theta},
$$

where $V^{*}$ denotes the stationary value of $V(t)$. The right-hand side of the previous equation is a monotonic function of $V^{*}$. Therefore, there is at most one value of $V(t)$ which generates a BGP equilibrium. Furthermore, given relationships (14) and (15) one can prove from (16) that there is a one-to-one correspondence between $V(t)$ and the growth rate of $K(t), h(t)$ and $C(t)$. Q.E.D.

The following proposition establishes the local stability property of the interior BGP:

PROPOSITION 2. Consider the economy described by Proposition 1. Consider the following subsets of $\Pi$ :

$$
\begin{aligned}
& \Pi_{1}=\{\pi \in \Pi \mid \beta>\alpha\}, \\
& \Pi_{2}=\left\{\pi \in \Pi \mid \alpha \theta<\beta<\alpha \text { and } \beta\left[(1-\theta)\left(1-s_{E}\right)+\theta\left(1-t_{h}-s_{w}\right)\right]<\alpha \theta\left(1-t_{h}-s_{w}\right)\right\}, \\
& \Pi_{3}=\left\{\pi \in \Pi \mid \alpha \theta<\beta<\alpha \text { and } \beta\left[(1-\theta)\left(1-s_{E}\right)+\theta\left(1-t_{h}-s_{w}\right)\right]>\alpha \theta\left(1-t_{h}-s_{w}\right)\right\}, \\
& \Pi_{4}=\left\{\pi \in \Pi \mid \beta<\alpha \theta \text { and } \beta\left[(1-\theta)\left(1-s_{E}\right)+\theta\left(1-t_{h}-s_{w}\right)\right]<\alpha \theta\left(1-t_{h}-s_{w}\right)\right\}, \\
& \Pi_{5}=\left\{\pi \in \Pi \mid \beta<\alpha \theta \text { and } \beta\left[(1-\theta)\left(1-s_{E}\right)+\theta\left(1-t_{h}-s_{w}\right)\right]>\alpha \theta\left(1-t_{h}-s_{w}\right)\right\} .
\end{aligned}
$$


(i) If $\pi \in \Pi_{1} \cup \Pi_{3} \cup \Pi_{4}$, then the equilibrium is locally saddle-path stable, i.e., there is locally a unique equilibrium fully determined by the initial conditions $K_{0}$ and $h_{0}$.

(ii) If $\pi \in \Pi_{2}$, then the equilibrium is locally indeterminate, i.e., there is locally a continuum of equilibria.

(iii) If $\pi \in \Pi_{5}$, then the equilibrium is locally unstable.

Proof. See the appendix. $\quad$ Q.E.D.

Figure 1 summarizes the previous result. The figure draws the different regions characterizing the local stability properties of the BGP in the $(\theta, \alpha)$ space while keeping the other parameters constant. We observe that in our model the local saddle-path stability of the BGP equilibrium does not hold for whole space of parameters. The previous equilibrium can also be either locally indeterminate or locally unstable. An interesting point of our stability result is that the existence of multiple equilibria requires that the government implement a specific combination of fiscal instruments. In absence of fiscal policy, the two curves defining the regions $\Pi_{2}$ and $\Pi_{5}$ coincide and, thus, these regions disappear. Furthermore, either increases in $s_{E}$ or reductions in $t_{h}$ and $s_{w}$ raise the region of indeterminacy and reduce the region of instability.

\section{[Insert Figure 1 around here]}

However, given this necessary intervention of the fiscal authority, the key for our result is the assumption that human capital accumulation uses a technology that combines intermediate market goods and non-working time. One can note that under either $\theta=0$ or $\theta=1$ the subsets of parameters $\Pi_{2}$ and $\Pi_{5}$ are both empty. Moreover, this is also the case when $\alpha=\beta$. In these 
extreme cases, the presence of growth-distorting fiscal policies never affects the stability property of the BGP equilibrium. 9

\section{Discussion}

What is the economic mechanism underlying the equilibrium dynamics described in the previous section? Since all prices are determined by the discounted marginal value of human capital alone (see (9) and (14)), and given the block-recursive structure of the dynamic system (16), equilibrium prices are determined independently of quantities. Furthermore, the dynamic behavior of those variables is dictated by the ranking of factor intensities across sectors. On the one hand, the adjustment process of equilibrium prices is stable if the production of intermediate goods and the activities accumulating human capital jointly employ a smaller relative quantity of physical capital. Otherwise, the previous process is unstable. This is because of the Stolper-Samuelson effect. If the production of new human capital is labor intensive, a sudden increase in the price of human capital raises the wage rate and, thus, the intertemporal no-arbitrage condition for the selection between physical and human capital investment will drive the relative price of human capital down. On the other hand, when physical capital commands a higher relative cost share in the production of new human capital, the quantity process is saddle-path stable. In the opposite case, this process is unstable. This stability property of the quantity process follows from the Rybczynski effect. If the production of new human capital is labor intensive, a sudden increase in the stock of human capital results in an increase in the production of new human capital and a decrease in the production of physical goods.

Therefore, regardless of the factor intensities of each sector, the BGP is locally saddle-path stable if and only if the rankings of factor intensities in the value and physical sense coincide. However, the

\footnotetext{
${ }^{9}$ Ortigueira (1998) proves that the presence of capital income taxation does not alter the saddle-path stability of the model with pure non-market human capital accumulation. Mino (1996) shows the same as the previous author for the model with pure market human capital accumulation. Finally, for the latter model, Alonso-Carrera (2000) proves that a subsidy to the purchases of new human capital does not affect the saddle-path stability result.
} 
taxation policy introduces a wedge between both rankings of factor intensities, so that the distortion from the taxation policy governs the stability property of the economic system. If the two factor intensity rankings still coincide, the BGP is locally saddle -path stable. By contrast, if the tax distortion is sufficiently high, the two rankings of factor intensities are no consistent and, thus, the BGP is either locally indeterminate or unstable.

To interpret the stability results given by Proposition 2 in terms of this reversal in the ranking of factor intensities, we substitute (3) in (4). Hence, using (A.3) from the appendix, and after a simple manipulation, we get the following reduced-form technology capturing the influence of the technologies for producing intermediate goods and for accumulating human capital:

$$
\dot{h}(t)=\gamma B^{\theta} \psi^{\theta(1-\alpha)}[(1-v(t)) K(t)]^{\alpha \theta}[(1-l(t)) h(t)]^{1-\alpha \theta}-\eta h(t) .
$$

Note that the sign of $\beta-\alpha \theta$ expresses the factor intensity ranking in the physical sense between the production of physical goods and the entire process of human capital accumulation, whereas the factor intensity ranking in the value sense is given by the sign of the following expression:

$$
\frac{\beta}{1-\beta}-\frac{\alpha \theta\left(1-t_{h}-s_{w}\right)}{(1-\theta)\left(1-s_{E}\right)+\theta(1-\alpha)\left(1-t_{h}-s_{w}\right)} .
$$

Thus, for example, if these two expressions are both positive, then the entire process of human capital accumulation is more human capital intensive than the production of physical goods in the physical and value sense.

Noting that the sign of (18) is given by the sign of the expression $\beta\left[(1-\theta)\left(1-s_{E}\right)+\theta\left(1-t_{h}-s_{w}\right)\right]-\alpha \theta\left(1-t_{h}-s_{w}\right)$, one can read Proposition 2 in terms of the duality between Rybczynski and Stolper-Samuelson effects. Hence, if $\alpha \theta<\beta$ and $\beta\left[(1-\theta)\left(1-s_{E}\right)+\theta\left(1-t_{h}-s_{w}\right)\right]<\alpha \theta\left(1-t_{h}-s_{w}\right)$, then the process governing the equilibrium value of human capital is stable and the quantity process is saddle-path stable. In this case, the BGP is therefore locally indeterminate. The previous two dynamic processes are both unstable if $\alpha \theta>\beta$ and $\beta\left[(1-\theta)\left(1-s_{E}\right)+\theta\left(1-t_{h}-s_{w}\right)\right]>\alpha \theta\left(1-t_{h}-s_{w}\right)$. Otherwise, the BGP is locally saddle-path 
stable since the two rankings of factor intensities coincides and, thus, an unstable process in prices or quantities is offset by adjustment in the other variable. In particular, one must observe that the two rankings coincide for any combination of the fiscal policy parameters when $\alpha=\beta$. Hence, we again observe that our two-stage process of human capital accumulation plays a crucial role in determining the stability results.

The unstable and the indeterminate equilibrium dynamics emerge in our model under conditions for the reversal in the factor intensity ranking that are the opposite of those found by Bond, Wang and Yip (1996). These authors obtain indeterminacy when the sector producing human capital is labor intensive in terms of factor cost shares but capital intensive in terms of factor quantity ratios. By contrast, we do not need a technology for human capital accumulation that is more physical capital intensive in terms of factor quantity ratios than that used for producing physical goods. The required condition for our result is that the sector producing intermediate goods would be more physical capital intensive than the physical good sector, i.e., $\alpha>\beta$. However, the reduced-form technology for producing new human capital must be less physical capital intensive than that for producing physical goods, i.e., $\alpha \theta<\beta$. Although it would remain to measure the plausibility of our technological restriction, this condition seems to be empirically less strong than the Bond, Wang and Yip's one. While the average share of physical capital in final output is usually calibrated around 0.4, Perli and Sakellaris (1998) estimate this share in final educational output at a range between 0.11 and 0.17 .

Relating with the previous discussion, we should also verify whether indeterminacy appears for plausible values of parameters. We next present a numerical example to illustrate that the combinations of parameters that lead to indeterminacy are empirically plausible. Suppose, for example, that $A=1, \quad B=1, \gamma=0.18, \rho=0.01, \quad \sigma=1.5, \delta=0.1, \eta=0.1, \quad \alpha=0.53$, $\beta=0.36, \theta=0.64, t_{k}=0.21, t_{h}=0.31, s_{E}=0.5$ and $s_{w}=0.08$. The values of $A, B, \delta, \eta$, $\beta, t_{k}$ and $t_{h}$ agree with those generally invoked in the economic literature (see, e.g., Jones, Manuelli and Rossi, 1993). OECD (1992) estimates for US that the public expenditure in secondary and higher levels of education amounts to $50 \%$ of total education expenditure in these 
levels, whereas the fellowships represent around $8 \%$ of the opportunity cost associated to these levels of education. ${ }^{10}$ These facts justify our choice of the values of $s_{E}$ and $s_{w}$. By recalling the estimation of Perli and Sakellaris (1998) given in Section 1, the value of $\theta$ was chosen so that the opportunity cost of accumulating human capital amounts to $31 \%$ of total educational cost along the BGP. We have jointly obtained the values of $\gamma, \rho$ and $\sigma$ by imposing that the after tax, net interest rate and the stationary growth rate equal to 0.04 and 0.02 at the BGP, respectively. Finally, the value of $\alpha$ was fixed in order to force the vector of parameters $\pi$ to lie in $\Pi_{2}$. Although the later value could seem a little large, the lack of reliable data prevents us from addressing a closed conclusion about the plausibility.

The possibility of multiple equilibria stands a chance to explain unpredictable differences in the growth patterns followed by countries with identical economic situations of departure. In particular, the present model predicts that identical economies with a specific fiscal policy structure may follow different equilibrium paths to reach a common long-run growth rate, so that each country's per capita income permanently diverges one from the other. Evidently, in our model, as in any endogenous growth model, fiscal policy can be a source of differences in both the long-run growth rate and in the growth patterns followed by otherwise identical economies. However, the present paper also predicts that two identical countries, even with the same fiscal policy structure, may follow different equilibrium paths. Intuitively, local indeterminacy of the equilibrium means that the expectations determine the equilibrium path since in this case the initial level of consumption and the allocation of time between different activities are freely chosen. Therefore, our economy becomes vulnerable to sunspot equilibria due to the presence of fiscal policy. In order words, indeterminacy is also able to account for business cycles without having to rely on shocks to fundamentals. ${ }^{11}$

\footnotetext{
${ }^{10}$ In this example, we identify, as is usual, the production of new human capital as education. We then ignore the investment in other concepts of human capital as, for instance, health.

11 The dependence of the stability property on the parameter structure may also lead to the existence of limit cycles. To check this point, we should follow a bifurcation analysis, which we have omitted since this is outside the scope of this paper.
} 
Evidently, when multiple equilib rium paths exist, they could be ranked by following the welfare criterion. However, the question is how individuals agree to select the equilibrium path generating the highest welfare. Equilibrium indeterminacy implies a problem of coordination failure. How do individuals coordinate their expectations for selecting an equilibrium path? This problem opens an interesting line for future research. We should look for alternative mechanisms of equilibrium selection, i.e., mechanisms through which individuals can coordinate their expectations. 


\section{Appendix}

\section{Reducing the explanatory variables of the model}

We will next solve for the factor intensities in each sector, the relative price and shares of both types

of capitals in each technology as functions of $K(t), h(t)$ and $V(t)$. First, diving (9a) by (9b), we have that

$$
z_{2}(t)=z_{1}(t)\left(\frac{\alpha(1-\beta)}{\beta(1-\alpha)}\right)
$$

Plugging the previous equation in (9a) and (9b), we respectively get

$$
\begin{aligned}
& z_{1}(t)=\left[\left(\frac{\alpha B}{\beta A}\right)\left(\frac{\alpha(1-\beta)}{\beta(1-\alpha)}\right)^{\alpha-1}\right]^{1 / \beta-\alpha} p(t)^{1 / \beta-\alpha}, \\
& z_{2}(t)=\left[\left(\frac{\alpha B}{\beta A}\right)\left(\frac{\alpha(1-\beta)}{\beta(1-\alpha)}\right)^{\beta-1}\right]^{1 / \beta-\alpha} p(t)^{1 / \beta-\alpha} .
\end{aligned}
$$

Introducing (A.1) and (A.2) in the non-arbitrage condition (11), we directly derive the relationship between $p(t)$ and $V(t)$ given by (14c). Moreover, Eqs. (14a) and (14b) are obtained by inserting (14c) in (A.1) and (A.2), respectively.

Second, we will use (14) to derive the allocations of both types of capitals to each sector as functions of $K(t), h(t)$ and $V(t)$. Dividing (13) by (11), and using (8) and (9), we get

$$
\frac{l(t)-u(t)}{1-l(t)}=\left(\frac{1-t_{h}-s_{w}}{1-s_{E}}\right)\left(\frac{\theta(1-\alpha)}{1-\theta}\right) .
$$

Moreover, full employment requires that

$$
u(t) z_{1}(t)+(l(t)-u(t)) z_{2}(t)=K(t) / h(t) .
$$


Solving the system composed of Eqs. (A.3) and (A.4) for $l(t)$ and $u(t)$, and rewriting the solution with (14), we derive (15a) and (15b). Expression (15c) is directly obtained from (15b) by noting that $z_{1}(t)=[v(t) K(t)] /[u(t) h(t)]$.

\section{Proof of Proposition 2}

We will proceed by following the standard method of writting the system defining the equilibrium dynamics in terms of stationary variables, as in Mulligan y Sala-i-Martin (1993) or Benhabib y Perli (1994). Thus, we first introduce two new variables: $z(t)=K(t) / h(t)$ and $x(t)=C(t) / K(t)$. Using dynamic system (16), we derive the dynamic equations describing the law of motion of the previous variables

$$
\begin{gathered}
\dot{z}(t)=z(t)\left\{A u(z(t), V(t)) z(t)^{-1}\left(z_{1}(V(t))\right)^{\beta}-x(t)-\delta\right. \\
\left.-\gamma B^{\theta} \Psi^{\theta}[1-l(z(t), V(t))]\left(z_{2}(V(t))\right)^{\alpha \theta}+\eta\right\}, \\
\dot{x}(t)=x(t)\left\{(1 / \sigma)\left(\left(1-t_{k}\right) \beta A\left[z_{1}(V(t))\right]^{\beta-1}-\delta-\rho\right)\right. \\
\left.-A u(z(t), V(t)) z(t)^{-1}\left(z_{1}(V(t))\right)^{\beta}+x(t)+\delta\right\} .
\end{gathered}
$$

Since the initial value of $z$ is fully defined by $K_{0}$ and $h_{0}$, the system of differential equations (A.5), (A.6) and (16d) fully summarizes the competitive equilibrium paths. To establish the local stability properties of the BGP equilibrium, we linearize this reduced system around the stationary values of $z(t), x(t)$ and $V(t)$, which will be denoted by $z^{*}, x^{*}$ and $V^{*}$. This linearized system is as follows:

$$
\left[\begin{array}{c}
\dot{z}(t) \\
\dot{x}(t) \\
\dot{V}(t)
\end{array}\right]=\left[\begin{array}{ccc}
a_{11} & a_{12} & a_{13} \\
a_{21} & a_{22} & a_{23} \\
0 & 0 & a_{33}
\end{array}\right]\left[\begin{array}{c}
z(t)-z^{*} \\
x(t)-x^{*} \\
V(t)-V^{*}
\end{array}\right],
$$

where the elements $a_{i j}$ are obtained from differentiating (A.5), (A.6) and (16d). The local stability is determined by the sign of the real part of the three eigenvalues associated with the Jacobian matrix (A.7). In particular, since the reduced system is composed of one state variable, $z(t)$, and two 
control variables, $x(t)$ and $V(t)$, the BGP equilibrium is locally saddle-path stable, locally unstable or locally indeterminate if the number of eigenvalues with negative real part is respectively equal to, smaller than or higher than one. These eigenvalues, which will be denoted by $\xi_{i}$, are the roots of the following characteristic polynomial:

$$
Q(\xi)=\left(a_{33}-\xi\right)\left\{\xi^{2}-\left(a_{11}+a_{22}\right) \xi+\left(a_{11} a_{22}-a_{12} a_{21}\right)\right\},
$$

where

$$
\begin{aligned}
& a_{11}=z^{*}\left\{-\frac{a_{21}}{x^{*}}+\frac{\gamma B^{\theta} \Psi^{\theta} z_{2}\left(V^{*}\right)^{\alpha \theta}}{z_{1}\left(V^{*}\right)+\Psi\left(z_{1}\left(V^{*}\right)-z_{2}\left(V^{*}\right)\right)}\right\}, \\
& a_{12}=-z^{*}, \\
& a_{21}=-\frac{A \Psi x^{*} z_{2}\left(V^{*}\right) z_{1}\left(V^{*}\right)^{\beta}\left(z^{*}\right)^{-2}}{z_{1}\left(V^{*}\right)+\Psi\left(z_{1}\left(V^{*}\right)-z_{2}\left(V^{*}\right)\right)}, \\
& a_{22}=x^{*}, \\
& a_{33}=-\left(\frac{\alpha \theta}{\beta-\alpha \theta}\right)\left[\left(1-t_{k}\right) \beta A z_{1}\left(V^{*}\right)^{\beta-1}-\delta+\eta\right]-\left(\frac{1-\beta}{\beta-\alpha \theta}\right)\left(1-t_{k}\right) \beta A z_{1}\left(V^{*}\right)^{\beta-1} .
\end{aligned}
$$

Using (14) and (15), and since $z^{*}>0, x^{*}>0$ and $V^{*}>0$, we obtain that $a_{12}<0, a_{22}>0$ and

$$
\begin{aligned}
& \operatorname{Sign}\left\{a_{11}\right\}=\operatorname{Sign}\left\{z_{1}\left(V^{*}\right)+\Psi\left(z_{1}\left(V^{*}\right)-z_{2}\left(V^{*}\right)\right)\right\}, \\
& \operatorname{Sign}\left\{a_{21}\right\}=\operatorname{Sign}\left\{(-1) a_{11}\right\}, \\
& \operatorname{Sign}\left\{a_{33}\right\}=\operatorname{Sign}\{(-1)(\beta-\alpha \theta)\},
\end{aligned}
$$

where the last equality comes from the fact that $\left(1-t_{k}\right) \beta A z_{1}\left(V^{*}\right)^{\beta-1}-\delta+\eta>0$, which is a necessary condition to $\dot{V}(t)=0$ be held along the BGP equilibrium. Moreover, using (14) and (15), and after some algebra, we get that,

$$
\operatorname{Sign}\left\{z_{1}\left(V^{*}\right)+\Psi\left(z_{1}\left(V^{*}\right)-z_{2}\left(V^{*}\right)\right)\right\}
$$




$$
=\operatorname{Sign}\left\{\beta\left(1-\mathrm{s}_{\mathrm{E}}\right)(1-\theta)+\theta(\beta-\alpha)\left(1-\mathrm{t}_{\mathrm{h}}-s_{w}\right)\right\} \text {. }
$$

At this point, one can easily prove Proposition 2. First, note that one of the roots of characteristic polynomial (A.8) is equal to $a_{33}$. Moreover, the other two roots are given by the eigenvalues associated with the sub-matrix obtained from dropping the last row and the last column of the Jacobian matrix (A.7). The trace and the determinant of this sub-matrix are equal to $\left(a_{11}+a_{22}\right)$ and

$\left(a_{11} a_{22}-a_{12} a_{21}\right)$, respectively. The sign of the eigenvalues of this sub-matrix are easily determined by noting that the trace and the determinant are respectively given by the sum and the product of these eigenvalues. If $\beta\left(1-\mathrm{s}_{\mathrm{E}}\right)(1-\theta)+\theta(\beta-\alpha)\left(1-\mathrm{t}_{\mathrm{h}}-s_{w}\right)>0$, then the trace and the determinant are both positive, such that the two eigenvalues have both positive real parts. Otherwise, the determinant is negative, and then the real parts of these two eigenvalues are of the opposite sign. Thus, the result directly follows.

\section{References}

Alonso-Carrera, J., 2000. The subsidy to human capital accumulation in a two-sector model of endogenous growth: A comparative dynamic analysis, Journal of Macroeconomics 22, 409431.

Benhabib, J., Farmer, R., 1999. Indeterminacy and sunspots in macroeconomics. In: Taylor, J., Woodford, M. (Ed.) Handbook of Macroeconomics. North Holland, Amsterdam.

Benhabib, J., Galí, J., 1995. On growth and indeterminacy: some theory and evidence, Carnegie Rochester Conference Series in Public Policy 43, 163-211.

Benhabib, J., Meng, Q., Nishimura, K., 2000. Indeterminacy under constant returns to scale in multisector economies, Econometrica 68, 1541-1548.

Benhabib, J., Perli, R., 1994. Uniqueness and indeterminacy: on the dynamics of endogenous growth, Journal of Economic Theory 63, 113-142. 
Bond, E., Wang, P., Yip, C., 1996. A general two-sector model of endogenous growth with human and physical capital: Balanced growth and transitional dynamics, Journal of Economic Theory 68, 149-173.

Drugeon, J.P., Poulsen, O., Venditti, A., 2002. On intersectoral allocations, factors substitutability and multiple long-run growth paths, forthcoming in Economic Theory.

Ghez R.G., Becker, G.S., 1975, The allocation of time and goods over the life cycle, NBER and Columbia University Press.

Heckman, J., 1976. A life-cycle model of earnings, leaming, and consumption, Journal of Political Economy84, S11-S44.

Jones, L., Manuelli, R., Rossi, P., 1993. Optimal taxation in models of endogenous growth, Journal of Political Economy. 101, 485-517.

Lucas, R., 1988. On the mechanics of economic development, Journal of Monetary Economy 22, 3-42.

Mino, K., 1996. Analysis of a two-sector model of endogenous growth with capital income taxation, International Economy Review 37, 227-253.

Mino, K., 2001. Indeterminacy and endogenous growth with social constant returns, Journal of Economic Theory 97, 203-222.

Mulligan, C.B. and X. Sala-i-Martin, 1993. Transitional dynamics in two-sector models of endogenous growth, Quarterly Journal of Economics 108, 739-773.

OECD, Education at a Glance: The OECD indicators, Paris, 1992.

Ortigueira, S., 1998. Fiscal policy in an endogenous growth model with human capital accumulation, Journal of Monetary Economy 42, 323-355.

Perli, R., Sakellaris, P., 1998. Human capital formation and business cycle persistence, Journal of Monetary Economy 42, 67-92.

Rebelo, S., Stokey, N. L., 1995. Growth effects of flat-rate taxes, Journal of Political Economy $103,519-550$.

Schultz, T.W., 1961. Investment in human capital, American Economic Review 51, 1-17. 


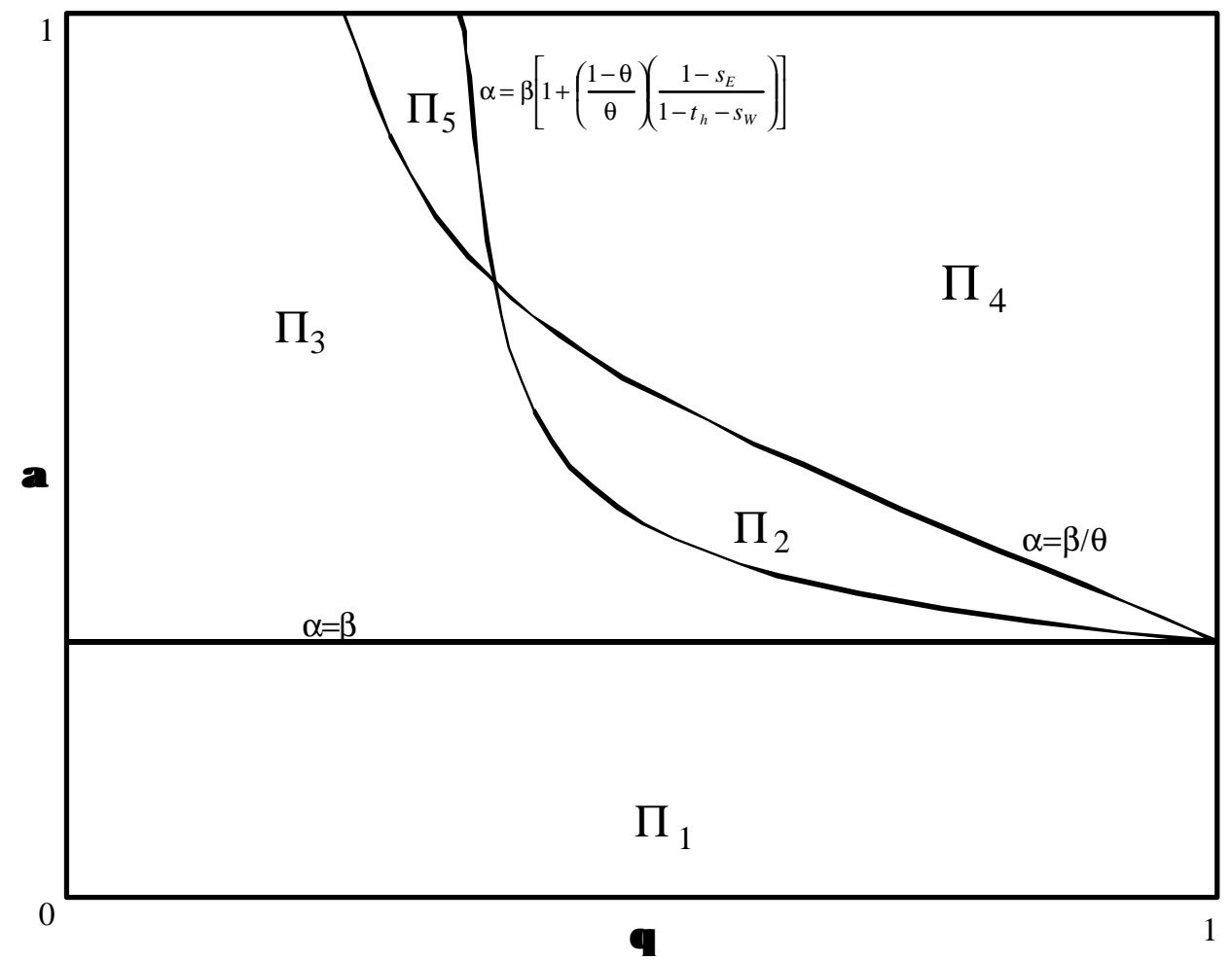

Fig.1. Local stability properties of the BGP 